\title{
The value of scintigraphy and ultrasonography in the preoperative localization of parathyroid glands in patients with primary hyperparathyroidism and concomitant thyroid disease
}

\author{
Theodore K. Alexandrides ${ }^{1}$, Konstantina Kouloubi ${ }^{1}$, Apostolos G. Vagenakis ${ }^{1}$, \\ Spyros Yarmenitis ${ }^{2}$, Trifon Spyridonidis ${ }^{3}$, Pavlos Vassilakos ${ }^{3}$ Dimitris Apostolopoulos ${ }^{3}$
}

${ }^{1}$ Endocrine Division, Department of Medicine, ${ }^{2}$ Department of Radiology and ${ }^{3}$ Department of Nuclear Medicine, Patras University Medical School, Rion-Patras, Greece

\begin{abstract}
Parathyroid scintigraphy and high-resolution ultrasonography are frequently used as preoperative localization procedures in primary hyperparathyroidism. However, when thyroid disease coexists, their diagnostic accuracy is probably abated. DESIGN: 56 patients with primary hyperparathyroidism were prospectively evaluated with parathyroid scintigraphy (with either thallium or technetium-99m agents or both) and 44 of them were also evaluated with ultrasonography. RESULTS: 33 patients $(59 \%)$ had coexistent thyroid disease. Upon operation, 48 patients were found to have a solitary parathyroid adenoma and were all cured. One patient had a carcinoma and 7 had multiglandular parathyroid disease. Regarding solitary lesions, the sensitivity of parathyroid scintigraphy with Tc-agents was $97 \%$ and thallium $78 \%$, while that of ultrasonography was $74 \%$. The false positive rate was $2.6 \%, 18 \%$ and $22 \%$, respectively. Concomitant thyroid disease had a non-significant effect on the results of parathyroid scintigraphy and ultrasonography. The efficiency of both modalities in diagnosing multiglandular disease was low (only 3/7 patients, 43\%). CONCLUSIONS: Parathyroid scintigraphy, in conjunction with Sestamibi or Tetrofosmin, constitutes the most sensitive localizing technique as regards solitary lesions. Ultrasonography is also useful in confirming scintigraphic findings, offers more precise anatomic information, and is valuable in the evaluation of concomitant thyroid disease. The complementary use of parathyroid scintigraphy and ultrasonography is beneficial and efficacious in areas with high prevalence of thyroid disease. The value of these modalities is considerably lower in multiglandular disease.
\end{abstract}

Key words: Concomitant thyroid disease, High-resolution ultrasonography, Parathyroid scintigraphy, Preoperative localization, Primary hyperparathyroidism

Address correspondence and requests for reprints to:

T.K. Alexandrides, M.D., Department of Medicine, Patras University Medical School, Rion-Patras, Greece 26500,

Tel.: +30-2610-999427, Fax: +30-2610-993982,

E-mail: thalex@med.upatras.gr

Received 18-10-05, Revised 30-11-05, Accepted 10-12-05

\section{INTRODUCTION}

The incidence of primary hyperparathyroidism in the general population is estimated to be $40 /$ 100,000 per year, and 4-5 times higher in postmenopausal women. ${ }^{1}$ Approximately $80-85 \%$ of the cases 
are due to solitary adenoma, $15 \%$ to hyperplasia of all glands, and $1 \%$ to parathyroid carcinoma. Surgical treatment is the only definitive therapy currently available. The success rate of surgery for adenomas is $95 \%$ in experienced hands, this currently being available in a few centers. ${ }^{2}$ Moreover, in some cases the enlarged parathyroid may be ectopic, e.g. within the mediastinum or the thyroid. The success rate of surgery in the case of parathyroid hyperplasia is considerably lower and the approach is different from that for solitary adenomas. A reliable localizing technique can help to increase the success rate and reduce the operating time, the frequency of reoperation and any surgical complications. Current trends towards a less invasive approach to parathyroidectomy, such as unilateral neck exploration or minimally invasive surgery, require precise preoperative localization techniques. ${ }^{3,4}$

Both scintigraphy and ultrasound (US) have been widely used in the preoperative localization of abnormal parathyroid glands. Thallium-201/technetium-99m scintigraphy has been utilized since the early 80 s, but its use has declined after the advent of novel technetium agents, mainly Sestamibi and Tetrofosmin, which offer lower radiation exposure and higher detection efficacy. ${ }^{5}$ However, a definitive recommendation for a particular tracer has not as yet been expressed. ${ }^{6}$ US with high-resolution transducers is widely available and has been claimed as efficacious for the detection of enlarged parathyroid glands. The results of scintigraphy and US have been compared with variable and occasionally contradictory results. ${ }^{7-12}$

Lower detection rates have been reported for both US and scintigraphy in the presence of thyroid disease or in cases of previous neck surgery. ${ }^{10-13}$ Both false negative and false positive results have been related to coexistent thyroid abnormalities. On the other hand, preoperative identification of concomitant thyroid disease is important, because surgical treatment of both thyroid and parathyroid disease can be undertaken at the same time.

In the present study, we investigated the diagnostic efficacy of high-resolution US and scintigraphy in a cohort of patients with high incidence of thyroid disease. The results in patients without thy- roid disease were compared with those obtained in patients with underlying thyroid pathology. Moreover, a comparison between radioactive agents was undertaken in order to define the optimal imaging technique.

\section{PATIENTS AND METHODS}

Fifty-six consecutive patients, 47 females and 9 males, aged $38-80$ years (mean age: $59 \pm 10.7$ years), with biochemical confirmation of primary hyperparathyroidism (raised serum calcium and PTH levels and normal renal function), evaluated by the authors, were included in the study. All patients were studied prospectively, were subjected to parathyroid surgery, and had histological examination of the surgical specimen. Normal calcium and PTH levels defined surgical cure during the follow-up period (mean \pm ISD: $52 \pm 30.5$ months). Biochemical determinations were carried out in the routine laboratory. The normal range of serum calcium ranged from 2.20 to $2.60 \mathrm{mmol} / \mathrm{L}$. Serum intact PTH was assayed by an immunoradiometric assay (Elsa-PTH, CIS bio international, France; normal range: 10-65 pg/ml).

\section{Ultrasonography}

High-resolution ultrasonography (US) was undertaken in 44 patients, either before or after scintigraphy. An experienced ultrasonographer (S.Y.) carried out all studies, blinded to the findings of scintigraphy. Parathyroid evaluation by US was carried out in the supine position with moderate extension of the neck using a machine equipped with a linear $10 \mathrm{MHz}$ high-resolution transducer and a curved array $7.5 \mathrm{MHz}$ transducer.

\section{Parathyroid scintigraphy}

Scintigraphic localization studies were undertaken in all patients, all studies being performed in the Department of Nuclear Medicine of our institution. During the years of the study, different radiopharmaceuticals and techniques were employed. Earlier studies $(n=27)$ were performed with the thallium-201/technetium-99m pertechnetate subtraction $\operatorname{scan}(\mathrm{Tl} / \mathrm{Tc}) .{ }^{99 \mathrm{~m}} \mathrm{Tc}-$ Tetrofosmin $(\mathrm{TF})$ and ${ }^{99 \mathrm{~m}} \mathrm{Tc}-S e s-$ tamibi (MIBI) were used in 22 and 33 patients, respectively. With the ${ }^{99 \mathrm{~m}} \mathrm{Tc}$-agents, both the thyroid subtraction and the double phase technique, were 
applied. Briefly, TF or MIBI was administered intravenously at a dose of $15 \mathrm{mCi}$, and images of the neck and the mediastinum were acquired at $10 \mathrm{~min}$ utes and at 2-3 hours post injection. Early and late images were compared for focal abnormalities and for areas of increased retention of the radioactive agent (double phase technique) ${ }^{14}$ Subsequently, a dose $(8 \mathrm{mCi})$ of ${ }^{99 \mathrm{~m}} \mathrm{Tc}-$ pertechnetate was administered for thyroid delineation and subtraction. In cases of suspected low uptake of the pertechnetate anion (thyroxin replacement therapy or iodine overload), the thyroid scan was performed on a different day and after proper manipulations. A dual head $\gamma$-camera (Helix, El Scint, Israel), equipped with a pinhole collimator on one head and a parallel-hole collimator on the other, was used for scintigraphy. Images of the neck were acquired through the pinhole collimator, while the mediastinum was viewed anteriorly by means of the parallel hole after an $180^{\circ}$ rotation of the gantry.

A number of patients included in the present study were also part of comparative studies between radiopharmaceuticals conducted in our institution $^{15,16}$ and were examined with two or three agents. Thus, 10 patients underwent both $\mathrm{Tl} / \mathrm{Tc}$ and TF scintigraphy and 1 patient $\mathrm{Tl} / \mathrm{Tc}$ and MIBI on the same day, 5 patients TF and MIBI on different days, and 5 patients were studied with all three agents.

Scintigraphic studies were reported as positive for parathyroid enlargement in a certain location if either the thyroid subtraction technique or the double phase technique or both produced a definite finding. Equivocal results were considered negative in the final evaluation. The Nuclear Medicine physicians interpreting the scan (P.V., A.D.) were aware of the clinical history and the biochemical profile of the patient but were blinded to the findings of the US. Palpation of the thyroid, in addition to the thyroid scan, was used for identification of thyroid abnormalities.

Statistical analysis was carried out by McNemar test, as applicable.

\section{RESULTS}

Thirty-three of the 56 patients $(59 \%)$ had coexistent thyroid disease. Four patients had previously been treated with radioiodine because of Graves' disease or relapsing Hashitoxicosis. Five patients had goitrous Hashimoto's thyroiditis, one had had total thyroidectomy followed by radioiodine ablation for papillary thyroid carcinoma, and the remaining 23 patients had nodular goiter.

One patient presented with recurrent hyperparathyroidism after two previous neck explorations 10 and 7 years earlier, when he had two enlarged parathyroid glands excised. In one patient, hyperparathyroidism was part of MEN 1 syndrome as she also had acromegaly. Another patient had been operated on in the past for pheochromocytoma and renal cell carcinoma.

\section{Surgery}

After surgery, 49 of the 56 patients $(87.5 \%)$ were found to have a solitary parathyroid lesion. The diagnosis was confirmed by histology and the postoperative resolution of the hyperparathyroidism. One of the lesions proved to be a parathyroid carcinoma. In five patients, multiglandular disease (MGD) was found during surgery and a total of 15 enlarged glands were removed: one patient with five hyperplastic glands, one with four, and three patients with two (one of them was the patient who had two of the parathyroids removed in previous neck explorations). All five patients are currently free of disease. Two patients currently have persistent hyperparathyroidism after surgical removal of one enlarged parathyroid gland. These two patients are considered to have MGD missed by the surgeon. Therefore, seven patients in total $(12.5 \%)$ were considered to have MGD.

All the enlarged parathyroid glands were orthotopic except for one located in the anterior mediastinum, residing inside the thymus, and two that were intrathyroidal. Information regarding the weight of the excised parathyroid gland was available in 50 of 64 surgically identified glands. The weight of the removed adenomas ranged from 0.06 to $12.62 \mathrm{~g}(2.13 \pm 2.9)$ and that of the hyperplastic glands from 0.06 to $3.8 \mathrm{~g}(0.97 \pm 1.04 \mathrm{~g})$. Twenty-three of the $47(49 \%)$ orthotopic adenomas originated from the left lower parathyroid gland, $12(25 \%)$ from the right lower, and the remaining 12 were equally distributed in the left and right upper parathyroid 
gland (13\% in each site).

\section{Scintigraphy}

\section{Solitary lesions}

Parathyroid scintigraphy (PS) localized correctly 48 of the 49 solitary lesions. Tl/Tc was performed in 23 patients and identified 18 (sensitivity: 78\%). Ninety-three percent of parathyroid adenomas weighing more than $500 \mathrm{mg}$, but only $43 \%$ of those weighing less than $500 \mathrm{mg}$ were preoperatively detected with $\mathrm{Tl} / \mathrm{Tc}(\mathrm{p}=0.006)$. The largest missed adenoma weighed $1700 \mathrm{mg}$, while the smallest detected weighed $60 \mathrm{mg}$. There were four false positive findings. Two of these were retrospectively attributed to non-functioning thyroid nodules, and the remaining to artefacts of the subtraction technique.

TF was performed in 19 patients and correctly localized all of them (sensitivity: 100\%). The smallest lesions detected by TF scanning weighed $157 \mathrm{mg}$. In the TF group, there were only 3 parathyroid adenomas weighing less $500 \mathrm{mg}$. There was one false positive finding (a small focus of extrathyroidal activity below the right thyroid lobe) in a patient with no concomitant thyroid disease. In the same patient, TF correctly identified a $380 \mathrm{mg}$ parathyroid adenoma in another location (below the left thyroid lobe).

MIBI was performed in 28 patients and identified 27 parathyroid adenomas (sensitivity: 96.4\%). There were no false positive findings. The smallest adenoma detected weighed $157 \mathrm{mg}$. All 18 lesions larger than $500 \mathrm{mg}$ and 9 out of $10(90 \%)$ of those weighing less than $500 \mathrm{mg}$ were correctly localized $(p=0.2)$. The adenoma missed with MIBI (a $380 \mathrm{mg}$ tumour) was detected with TF. However, in the same patient, unlike TF, no false positive finding was produced.

The combined sensitivity for the Tc-agents (TF and MIBI) was $97 \%$ and was better than that of $\mathrm{Tl} /$ Tc $(p=0.043)($ Table 1). Four of the 5 adenomas missed by $\mathrm{Tl} / \mathrm{Tc}$ were detected with $\mathrm{TF}$ and/or MIBI. In the fifth case, no second scan was performed and this was the only case where preoperative scintigraphy failed to localize an adenoma. One of the solitary lesions proved to be a parathyroid carcinoma. The patient had Graves' disease and had received radioactive iodine in the past. MIBI was positive and the kinetics of the MIBI uptake by the tumour was consistent with parathyroid tissue. The false positive rate for $\mathrm{Tl} / \mathrm{Tc}$ was $18 \%$ and for Tc agents $2.6 \%$.

Concomitant thyroid disease had no effect on the results of scintigraphy (Table 3). The single adenoma not detected by MIBI was in a patient with normal thyroid gland. $\mathrm{Tl} / \mathrm{Tc}$ failed to identify the adenoma in 3 of 10 subjects with and in 2 of 13 subjects without thyroid pathology. False positive findings occurred in 4 cases with $\mathrm{Tl} / \mathrm{Tc}$ (two of the patients had concomitant thyroid disease), in one case with TF (in a patient with no thyroid disease) and in none with MIBI.

\section{Multiglandular disease}

Presurgical scanning visualized three glands in the patient with five-gland hyperplasia (MIBI), four glands in the patient with four-gland hyperplasia (MIBI), two glands in the patient who had the other two parathyroids removed in previous surgical explorations ( $\mathrm{TF}$ identified two lesions, while $\mathrm{Tl} / \mathrm{Tc}$ detected one lesion), one gland in each of the two patients who had two parathyroids removed and

Table 1. Parathyroid scintigraphy: Comparison between thallium and Tc-99m agents

\begin{tabular}{|c|c|c|c|c|c|c|c|}
\hline & \multicolumn{3}{|c|}{ TL/TC } & \multicolumn{4}{|c|}{ TC-AGENTS } \\
\hline & $\begin{array}{l}\text { Patients } \\
\text { (Lesions) }\end{array}$ & $\begin{array}{c}\text { True } \\
\text { Positive } \\
\text { (Sensitivity) }\end{array}$ & $\begin{array}{c}\text { False } \\
\text { Positive } \\
\text { (Rate) }\end{array}$ & $\begin{array}{l}\text { Patients } \\
\text { (Lesions) }\end{array}$ & $\begin{array}{c}\text { True } \\
\text { Positive } \\
\text { (Sensitivity) }\end{array}$ & $\begin{array}{c}\text { False } \\
\text { Positive } \\
\text { (Rate) }\end{array}$ & $\begin{array}{c}\text { Statistical } \\
\text { Difference in } \\
\text { Sensitivity (p) }\end{array}$ \\
\hline Solitary lesions & $23(23)$ & $18 / 23(0.78)$ & $4 / 22(0.18)$ & $39(39)$ & $38 / 39(0.97)$ & $1 / 39(0.026)$ & 0.043 \\
\hline $\begin{array}{l}\text { Multiglandular } \\
\text { involvement }\end{array}$ & $4(6)$ & $2 / 6(0.33)$ & $6(16)$ & $11 / 16(0.69)$ & & & \\
\hline Total lesions & $27(29)$ & $20 / 29(0.69)$ & $4 / 24(0.17)$ & $45(55)$ & 49/55 (0.89) & $1 / 50(0.02)$ & 0.047 \\
\hline
\end{tabular}


were considered cured $(\mathrm{Tl} / \mathrm{Tc}$ and $\mathrm{TF}$ in both patients, with identical findings) and, finally, it was negative in the last two patients (TF alone and Tl/ Tc alone, in each patient, respectively). The last two patients had one gland removed each and were not cured. More specifically, of the 17 surgically removed glands, $\mathrm{Tl} / \mathrm{Tc}$ identified 2 of the 6 (sensitivity $33.3 \%$ ), weighing $260 \mathrm{mg}$ and $310 \mathrm{mg}$, respectively. TF localized 3 of the 5 (sensitivity $60 \%$ ) the smallest $260 \mathrm{mg}$. MIBI detected 8 of the 12 (sensitivity $67 \%$ ); among these cases there were two very small glands weighing $70 \mathrm{mg}$ and $100 \mathrm{mg}$.

The combined sensitivity for Tc-agents was $69 \%$ (Table 1 ). However, in only 3 of the 6 patients $(50 \%)$ was the MGD disease correctly predicted preoperatively, by the presence of multiple positive findings. One of the glands that MIBI failed to visualize was intrathyroidal. Six of the patients additionally had thyroid disease and the seventh is the patient with the two previous neck explorations. There were no false positive findings. The actual sensitivity of the different scintigraphic procedures is expected to be somewhat lower than that indicated above, because surgery failed to identify and remove all the hyperfunctioning glands.

In conclusion, the overall sensitivity of the three scintigraphic techniques, for both solitary and multiglandular parathyroid disease, was: MIBI: $87.5 \%$, TF: $91.6 \%$ (combined sensitivity for Tc-agents: $89 \%$ ) and $\mathrm{Tl} / \mathrm{Tc}: 69 \%(\mathrm{p}=0.047)$ (Table 1$)$.

\section{Ultrasonography}

\section{Solitary lesions}

Thirty-eight patients of the 49 with solitary lesion underwent US imaging preoperatively and 28 adenomas were correctly visualized (sensitivity:
$74 \%$, Table 2). US identified $71 \%$ of adenomas weighing less than $500 \mathrm{mg}$ while it identified $78 \%$ of the adenomas larger than $500 \mathrm{mg}(\mathrm{p}=0.6)$. US was falsely negative in 10 of the 38 patients. Four of them had concomitant thyroid disease. One the 6 patients with normal thyroid and negative US had an ectopic adenoma within the mediastinum. The false positive findings were 8 out of 36 (false positive rate: $22 \%$, Table 2), two of them in patients with thyroid disease. Concomitant thyroid disease had no effect on US sensitivity and accuracy (Table 3 ). US identified the single adenoma missed by $\mathrm{Tl} / \mathrm{Tc}$ scintigraphy, thus the combined PS and US sensitivity for solitary lesions was $100 \%$.

\section{Multiglandular disease}

Preoperative US was carried out in 6 of the 7 patients and localized correctly 9 of the 15 lesions (sensitivity 60\%, Table 2). All the patients with MGD had concomitant thyroid disease in this group. There was only one false positive finding (false positive rate: $10 \%$, Table 2 ). US correctly predicted multiglandular involvement in only $2 / 6$ patients.

Combined PS and US resulted in $73 \%$ sensitivity on a lesion basis. However, the rate of the predicted MGD was not raised (50\% with US combined with Tc-agents). The overall sensitivity of US, for both single and MGD, was $70 \%$ (Table 2).

\section{DISCUSSION}

In the present study, PS proved to be of considerable sensitivity and accuracy in localizing solitary lesions. Tl/Tc imaging sensitivity was $78 \%$, a figure that is among the highest reported in the literature. ${ }^{17-18}$ TF imaging sensitivity was $100 \%$ and that of MIBI was $96 \%$. Combined sensitivity of PS and Tc-agents

Table 2. Comparison between parathyroid scintigraphy and high-resolution ultrasound

\begin{tabular}{|c|c|c|c|c|c|c|c|c|}
\hline & \multirow[b]{2}{*}{$\begin{array}{l}\text { Patients } \\
\text { (Lesions) }\end{array}$} & \multicolumn{2}{|c|}{ ULTRASOUND } & \multicolumn{4}{|c|}{ SCINTIGRAPHY } & \multirow[b]{2}{*}{$\begin{array}{c}\text { Difference } \\
\text { in Sensitivity } \\
\text { (p) }\end{array}$} \\
\hline & & $\begin{array}{c}\text { True } \\
\text { Positive } \\
\text { (Sensitivity) }\end{array}$ & $\begin{array}{c}\text { False } \\
\text { Positive } \\
\text { (Rate) }\end{array}$ & $\begin{array}{c}\text { True } \\
\text { Positive } \\
\text { (Sensitivity) }\end{array}$ & $\begin{array}{l}\text { False } \\
\text { Positive } \\
\text { (Rate) }\end{array}$ & $\begin{array}{c}\text { SCAN (+) } \\
\text { US (-) }\end{array}$ & $\begin{array}{c}\text { SCAN (-) } \\
\text { US (+) }\end{array}$ & \\
\hline Solitary lesions & $38(38)$ & $28 / 38(0.74)$ & $8 / 36(0.22)$ & $37 / 38(0.97)$ & $3 / 40(0.075)$ & 10 & 1 & 0.016 \\
\hline Multiglandular & $6(15)$ & $9 / 15(0.60)$ & $1 / 10(0.10)$ & $9 / 15(0.60)$ & 0 & 1 & 1 & - \\
\hline Total & $44(53)$ & $37 / 53(0.70)$ & $9 / 46(0.20)$ & $46 / 53(0.87)$ & $3 / 49(0.06)$ & 11 & 2 & 0.027 \\
\hline & & & & & \multicolumn{4}{|c|}{ 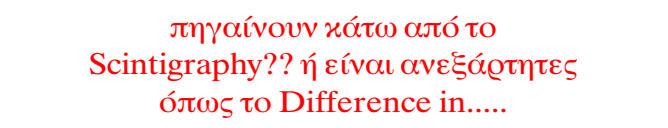 } \\
\hline
\end{tabular}


Table 3. Scintigraphic and sonographic findings in patients with and without concomitant thyroid disease.

\begin{tabular}{|c|c|c|c|c|c|c|c|}
\hline & \multicolumn{3}{|c|}{ THYROID DISEASE } & \multicolumn{3}{|c|}{ NO THYROID DISEASE } & \multirow{2}{*}{$\begin{array}{r}\text { Statistical } \\
\text { Difference } \\
\text { of Sensitivity } \\
\text { (p) }\end{array}$} \\
\hline & $\begin{array}{l}\text { Patients } \\
\text { (Lesions) }\end{array}$ & $\begin{array}{c}\text { True } \\
\text { Positive } \\
\text { (Sensitivity) }\end{array}$ & $\begin{array}{c}\text { False } \\
\text { Positive } \\
\text { (Rate) }\end{array}$ & $\begin{array}{l}\text { Patients } \\
\text { (Lesions) }\end{array}$ & $\begin{array}{c}\text { True } \\
\text { Positive } \\
\text { (Sensitivity) }\end{array}$ & $\begin{array}{c}\text { False } \\
\text { Positive } \\
\text { (Rate) }\end{array}$ & \\
\hline \multicolumn{8}{|l|}{ SCINTIGRAPHY } \\
\hline Solitary lesions & $27(27)$ & 26/27 (0.96) & $1 / 27(0.04)$ & $22(22)$ & $22 / 22(1.0)$ & $2 / 24(0.08)$ & 1.0 \\
\hline $\begin{array}{l}\text { Multiglandular } \\
\text { involvement }\end{array}$ & $6(15)$ & $9 / 15(0.60)$ & 0 & $1(2)$ & $2 / 2(1.0)$ & 0 & \\
\hline Total lesions & $33(42)$ & $35 / 42(0.83)$ & $1 / 36(0.03)$ & $23(24)$ & $24 / 24(1.0)$ & $2 / 26(0.08)$ & 0.04 \\
\hline \multicolumn{8}{|c|}{ ULTRASONOGRAPHY } \\
\hline Solitary lesions & $20(20)$ & $16 / 20(0.80)$ & $3 / 19(0.16)$ & $18(18)$ & $12 / 18(0.67)$ & $6 / 18(0.33)$ & 0.47 \\
\hline $\begin{array}{l}\text { Multiglandular } \\
\text { involvement }\end{array}$ & $6(15)$ & $9 / 15(0.60)$ & $1 / 10(0.10)$ & 0 & - & - & - \\
\hline Total lesions & $26(35)$ & $25 / 35(0.71)$ & $4 / 29(0.14)$ & $18(18)$ & $12 / 18(0.67)$ & $6 / 18(0.33)$ & 0.97 \\
\hline
\end{tabular}

was $97 \%$. The positive predictive value of PS and Tc-agents for single gland involvement was high (95\%). Only 2 of 40 patients with a single finding on scintigraphy proved to have MGD. According to a review of the relevant literature from 1996 to 2000, ${ }^{9}$ sensitivity of PS in detecting abnormal glands has reached a percentage of $77-100 \%$ for solitary tumours (mean: 87\%). Imaging with TL/Tc was not included, since it has proven inferior compared to MIBI or TF.

US sensitivity was $74 \%$ in solitary lesions, comparable to that of $\mathrm{Tl} / \mathrm{Tc}$ scanning and inferior to PS with Tc-agents $(p=0.016$, Table 2$)$. The high sensitivity of Tc-agents for solitary lesions (97\%) could not be further increased significantly by combining the results of US. However, US confirmed the majority of scintigraphic results, thus increasing the confidence of the clinicians in the findings, and offered more detailed information on the size and the location of detected parathyroid lesions. An important contribution of US is that it delineates focal thyroid abnormalities better than the thyroid scan, and the presence of concomitant thyroid disease affects the surgical approach, since a different operation for both thyroid and parathyroid disease is scheduled in such cases. This is of the utmost importance in areas with high prevalence of thyroid disease. Consequently, the preoperative combination of the two localization procedures, while not improving sensitivity as compared to scintigraphy alone, affords other advantages.

Regarding multiglandular parathyroid disease, localization techniques in our study were not as satisfactory as in the case of single-gland disease. The estimated sensitivity in detecting abnormal parathyroid glands was only $33 \%$ for $\mathrm{Tl} / \mathrm{Tc}$ and ranged from $60 \%$ to $67 \%$ for MIBI, TF, and US. The presence of multiple findings on scintigraphy with Tc agents was observed in only 3 of 6 patients with MGD, while in another case the indication of MGD was incorrect (a second focal finding was falsely positive). Combined sensitivity for PS and US reached $73 \%$ on a lesion basis, but this increase was not significant and, moreover, the prediction of MGD remained low $(50 \%)$. Even if a significant proportion of patients $(89 \%)$ were correctly classified as having single or multiple gland disease, this was actually due to the high prevalence of single gland disease $(87.5 \%)$. Data from other studies, reviewed by Lumachi et al, ${ }^{9}$ show that in patients with MGD, MIBI sensitivity is $57 \%$ on average, a value comparable to our results. This contrasts with the conclusion reached by other authors, ${ }^{23,24}$ that the use of Sestamibi imaging may allow differentiation of hyperplasia from adenoma. Johnston et al, ${ }^{23}$ in a population with $13 \%$ incidence of hyperplasia, were able to identify 5 of the 6 patients with MGD and 34 of 38 $(89.5 \%)$ with single-gland involvement, based on the findings of MIBI. However, as in our work, the absolute number of patients with MGD was small. In 
the series of Caixas et al, ${ }^{24}$ MIBI scan identified $100 \%$ of cases with single-gland involvement and $61 \%$ of patients with MGD. However, patients with secondary hyperparathyroidism were also included in that study. If the latter were excluded, this denotes that MIBI correctly indicated MGD in only 3 out of 9 patients (33\%).

One of the 4-hyperfunctioning glands missed by MIBI in our study was intrathyroidal in a patient with toxic multinodular goiter (MNG). US has been reported to be of value in characterizing intrathyroidal parathyroids, ${ }^{22}$ however, in our case US played no contributory role, possibly because of the multinodular appearance of the thyroid gland.

Our findings are of special interest with regard to the high frequency of concomitant thyroid pathology, since 27 of the 49 patients $(55 \%)$ with solitary parathyroid lesions and 6 of the 7 the patients with multiglandular involvement had coexistent thyroid disease. Many investigators have reported that thyroid nodules, thyroid adenomas, and papillary or Hürthle cell carcinomas can be falsely interpreted as hyperfunctioning parathyroid glands on $\mathrm{Tl} / \mathrm{Tc},{ }^{19}$ $\mathrm{MIBI}^{20,21}$ or TF, ${ }^{15}$ thus influencing the specificity of PS. On the other hand, thyroid nodules, hot on Tc scanning, lead to false positive findings in subtraction PS with $\mathrm{Tl} / \mathrm{Tc}$, TF or $\mathrm{MIBI}^{19}$ because of suppression of the signals of the normal thyroid parenchyma.

In our series, scintigraphy was highly sensitive and specific in detecting solitary parathyroid lesions, even in the presence of coexistent thyroid disease (Table 3). When findings in MGD were included (6 of 7 of those patients had coexistent thyroid abnormalities), sensitivity was apparently lower in the thyroid disease group (Table 3), but this was obviously caused by the lower detection rates in the presence of MGD and not by the coexistence of thyroid disease. The false positive rate of scintigraphy with Tcagents was low $(2 \%)$. Although a number of nonfunctioning thyroid nodules showed uptake of MIBI and TF, false positive interpretations were avoided by careful palpation of the thyroid and inspection of the findings of the thyroid scan. Unless grossly enlarged, parathyroid lesions usually do not produce "cold" areas on the thyroid scan and are rarely pal- pable. Moreover, the uptake of TF and MIBI in nodules relative to the thyroid was invariably low in this series, whereas the uptake in parathyroid lesions was high in most of the cases. When MIBI is used, the implementation of the double phase technique can possibly differentiate parathyroid from thyroid abnormalities. However, a number of parathyroid lesions show rapid washout of MIBI and, consequently, a gain in specificity would result in a loss of sensitivity. ${ }^{11,16,21}$ We cannot draw conclusions from the present study on this issue, because the results of the double phase technique were not interpreted blinded to the subtraction method, while the corresponding findings were not reported separately.

Autonomously functioning thyroid nodules also did not affect scintigraphic results. In all 6 cases where such nodules were observed, the suppressed thyroid tissue was prominent on the MIBI or TF images, but was not misinterpreted as parathyroid abnormality. Intense focal uptake of the radiopharmaceutical at the site of the parathyroid abnormality, exceeding the signal of the suppressed thyroid parenchyma, was noticed in 4 cases in the parathyroid adenoma group. In two patients with coexisting MGD and toxic MNG, MIBI correctly detected all four hyperplastic parathyroid glands in the first case, and one of the two enlarged glands in the second case.

The accuracy of US was also not influenced by the presence of thyroid disease, as there was no significant difference in terms of sensitivity and false positive rate between the groups with and without thyroid disorders (Table 3). A single radiologist performed all the US studies in this series. Results could be different if more than one interpreter were involved, since US is highly operator dependent. In the literature, US imaging sensitivities exhibit a greater variance among studies and reported values range from $30 \%$ to $90 \%,{ }^{13,25}$ with the highest success rates relating to adenomas. ${ }^{22,26}$ Multinodular goitre poses difficulties in interpreting US findings: parathyroid adenomas adjacent to the dorsal surface of the thyroid glands are occasionally missed owing to the similarly reduced echo density of the thyroid nodules in MNG. ${ }^{19}$ Although there are different estimations as to whether concomitant thy- 
roid disease has a statistically significant negative influence in PS and US sensitivity, $8,10,11,13,19,20,26$ information obtained by PS and US can be complementary to each other so that combination of the two techniques is frequently suggested, especially in populations with high prevalence of thyroid nodular disease. ${ }^{8,19,25}$ US is more accurate than both palpation and the thyroid scan for the identification of thyroid nodules and can facilitate the interpretation of scintigraphic findings. In the present study, the combination of the two modalities was not used in this way in order to achieve a blinded reading. We must also bear in mind that US is not only essential in delineating the thyroid gland and revealing and characterizing thyroid abnormalities, ${ }^{27,28}$ but additionally offers the advantage of defining the anatomy surrounding the thyroid/parathyroid structures, ${ }^{29}$ while surgeon expertise can validate even a "negative" US in order to postulate the possible location of an abnormal parathyroid gland not visible on US. ${ }^{30}$

The weight of hyperfunctioning parathyroids is reported as a factor limiting PS sensitivity. In fact, most noninvasive localization methods exhibit decreasing sensitivity, with diminishing size of parathyroid glands. ${ }^{2,29,31,32}$ However, additional factors, such as vascularity, mitochondrial content, metabolic activity, certain location, etc., influence detectability. These factors may explain the fact that very small adenomas, e.g. the $75 \mathrm{mg}$ weight in the study of Caixas, ${ }^{24}$ have been detected with MIBI, even though the same radionuclide had failed to identity much larger glands, e.g. the $1700 \mathrm{mg}$ gland in Thule's study. ${ }^{2} \mathrm{We}$ found that MIBI was equally sensitive in identifying either small $(<500 \mathrm{mg})$ or larger adenomas. Despite the low detectability rates in patients with MGD, two very small hyperplastic glands were also detected. Concerning TF, our data are not conclusive as only a small number of patients with small parathyroid adenomas had undergone TF scan preoperatively. $\mathrm{Tl} / \mathrm{Tc}$ was less sensitive in detecting small lesions, although a small adenoma and two small hyperplastic glands were visualized.

The indisputable value of PS is the detection of ectopic parathyroid lesions. We were confronted with one case of an adenoma within the mediastinum and MIBI correctly localized it. Though the prevalence of ectopic hyperfunctioning parathyroids is generally below $10 \%$, it is certainly significant to bear in mind when addressing the question of the usefulness of preoperative localization methods.

A rather unexpected finding in our series is that $50 \%$ of parathyroid adenomas occurred in the left lower position, while a quarter were located in the right lower position, the second most frequent location. The knowledge that parathyroid adenomas are more frequently located in the lower glands than the upper is well established,${ }^{34}$ but the predominance of the left lower gland has not been previously reported. We cannot offer a plausible explanation for this finding.

In regard to the high prevalence of thyroid disease found in our patients, this is in accordance with a recently published retrospective multicenter study from Italy. ${ }^{35}$ Higher frequency of nodular goiter is reported among patients with primary hyperparathyroidism $(51.5 \%)$ as compared to the general population (5-19\%) and to patients with secondary hyperparathyroidism $(38.2 \%)$. The same study also reported no difference in the frequency of thyroid disease between sexes and ages in the subgroup of primary hyperparathyroidism. Two more studies, one from Spain $^{36}$ and one from Japan, ${ }^{13}$ have also reported similar findings concerning the prevalence of thyroid disease in primary hyperparathyroidism.

In conclusion, PS in conjunction with Sestamibi or Tetrofosmin yields high sensitivity and specificity with regard to solitary lesions. US is also valuable in confirming scintigraphic findings, in offering more precise anatomic information and, more importantly, in revealing of concomitant thyroid disease. The complementary use of PS and US is a reliable noninvasive localization technique in areas with high prevalence of thyroid disease that should be considered in every patient with primary hyperparathyroidism undergoing surgery.

\section{REFERENCES}

1. Heath H, 1991 Primary hyperparathyroidism: recent advances in pathogenesis, diagnosis, and management. Advances in Internal Medicine 37: 275-293.

2. Thule P, Thakore K, Vansant J, McGarity W, Weber C, Phillips LS, 1994 Preoperative localization of parathyroid tissue with technetium-99m sestamibi 123-I 
subtraction scanning. J Clin Endocrinol Metab 78: 7782.

3. Denham DW, Norman J, 1998 Cost-effectiveness of preoperative sestamibi scans for primary hyperparathyroidism is dependent solely upon the surgeon's choice of operative procedure. J Am Coll Surg 186: 293-305.

4. Casara D, Rubello D, Pelizzo MR, Shapiro B, 2001 Clinical role of ${ }^{99} \mathrm{TcO}_{4} / \mathrm{MIBI}$ scan, ultrasound and intra-operative gamma probe in the performance of unilateral and minimally invasive surgery in primary hyperparathyroidism. Eur J Nucl Med 28: 1351-1359.

5. O’Doherty MJ, 1997 Radionuclide parathyroid imaging [Editorial]. J Nucl Med 38: 840-841.

6. Greenspan BS, Brown ML, Dillehay GL, et al, 1998 Procedure guideline for parathyroid scintigraphy. J Nucl Med 39: 1111-1114.

7. Chapuis Y, Fulla Y, Bonnichon P, et al, 1996 Values of ultrasonography, sestamibi scintigraphy, and intraoperative measurement of 1-84 PTH for unilateral neck exploration of primary hyperparathyroidism. World J Surg 20: 835-839.

8. DeFeo ML, Colagrande S, Biagini C, et al, 2000 Parathyroid glands: combination of 99mTc MIBI scintigraphy and US for demonstration of parathyroid glands and nodules. Radiology 214: 393-402.

9. Lumachi F, Zucchetta P, Marzola MC, et al, 2000 Advantages of combined technitum-99m-sestamibi scintigraphy and high-resolution ultrasonography in parathyroid localization: comparative study in 91 patients with primary hyperparathyroidism. Eur J Endocrinol 143: 755-760.

10. Mazzeo S, Caramella D, Lencioni R, et al, 1996 Comparison among sonography, double-tracer subtraction scintigraphy, and double-phase scintigraphy in the detection of parathyroid lesions. AJR Am J Roentgenol 166: 1465-1470.

11. Krausz Y, Lebensart PD, Klein M, et al, 2000 Preoperative localization of parathyroid adenoma in patients with concomitant thyroid nodular disease. World J Surg 24: $1573-1578$.

12. Jaskowiak N, Norton JA, Alexander HR, et al, 1996 A prospective trial evaluating a standard approach to reoperation for missed parathyroid adenoma. Ann Surg 224: 308-320.

13. Masatsugu1 T, Yamashita H, Noguchi S, et al, 2005 Significant clinical differences in primary hyperparathyroidism between patients with and those without concomitant thyroid disease. Surg Today 35: 351-356.

14. Taillefer R, Boucher Y, Potvin C, Lambert R, 1992 Detection and localization of parathyroid adenomas in patients with hyperparathyroidism using a single radionuclide imaging procedure with technetium-99msestamibi (double phase study). J Nucl Med 1992 33: 1801-1807.

15. Apostolopoulos DJ, Houstoulaki E, Giannakenas C, et al, 1998 Technetium-99m-tetrofosmin for parathy- roid scintigraphy: comparison to thallium-technitium scanning. J Nucl Med 39: 1433-1441.

16. Apostolopoulos DJ, Spyridonidis TJ, Giannakenas CC, et al, 2003 Parathyroid scintigraphy with ${ }^{99 \mathrm{~m}} \mathrm{Tc}$-Sestamibi and ${ }^{99 m}$ Tc-Tetrofosmin: Comparison of diagnostic efficacy and kinetics. World J Nucl Med 2: 182-190.

17. Sandrock D, Merino MJ, Norton JA, Neumann RD, 1990 Parathyroid imaging by Tc/TL scintigraphy. Eur J Nucl Med 16: 607-613.

18. Coakley AJ, 1995 Parathyroid imaging. Nucl Med Commun 16: 522-533.

19. Klingler PJ, Strolz S, Profanter C, et al, 1998 Management of hyperparathyroidism in an endemic goitre area. World J Surg 22: 301-308.

20. Hindie E, Melliere D, Simon D, Perlemuter L, Galle P, 1995 Primary hyperparathyroidism: Is technetium 99m-sestamibi/iodine-123 subtraction scanning the best procedure to locate enlarged glands before surgery? J Clin Endocrinol Metab 80: 302-307.

21. McBiles M, Lambert AT, Cote MC, Kim SY, 1995 Sestamibi parathyroid imaging. Semin Nucl Med 25: 221234.

22. Norton JA, Sugg SL 1994 Surgical management of hyperparathyroidism. In: DeGroot LJ (ed). Endocrinology, Philadelphia, WB Saunders Company; pp, 11061122.

23. Johnston LB, Carroll MJ, Britton KE, et al, 1996 The accuracy of parathyroid gland localization in primary hyperparathyroidism using sestamibi radionuclide imaging. J Clin Endocrinol Metab 81: 346-352.

24. Caixas A, Berna L, Hernandez A, et al, 1997 Efficacy of preoperative diagnostic imaging localization of technetium 99m-sestamibi scintigraphy in hyperparathyroidism. Surgery 121: 535-541.

25. Giordano A, Rubello D, Casara D, 2001 New trends in parathyroid scintigraphy. Eur J Nucl Med 28: 14091420.

26. Ulanovski D, Feinmesser R, Cohen M, et al, 2002 Preoperative evaluation of patients with parathyroid adenoma: Role of high-resolution ultrasonography. Head Neck 24: 1-5.

27. Staudenherz A, Abela C, Niederle B, et al, 1997 Comparison and histopathological correlation of three parathyroid imaging methods in a population with a high prevalence of concomitant thyroid diseases. Eur J Nucl Med 24: 143-149.

28. Ishibashi M, Nishida H, Strauss HW, et al, 1997 Localization of parathyroid glands using technetium-99mtetrofosmin imaging. J Nucl Med 38: 706-711.

29. Varverakis E, Neonakis E, 2002 Contribution of highresolution ultrasonography in the differential diagnosis of benign from malignant thyroid nodules. HORMONES 1: 51-56.

30. Shen W, Sabanci U, Morita ET, et al, 1997 Sestamibi scanning is inadequate for directing unilateral neck exploration for first-time parathyroidectomy. Arch 
Surg 132: 969-976.

31. Bhatnagar A, Vezza PR, Bryan JA, Atkins FB, Ziessman HA, 1998 Technetium-99m-sestamibi parathyroid scintigraphy: effect of P-glycoprotein, histology and tumor size on detectability. J Nucl Med 39: 1617-1620.

32. McHenry CR, Lee K, Saadey J, Neumann DR, Esselstyn CB Jr, 1996 Parathyroid localization with technetium-99m-sestamibi: a prospective evaluation. J Am Coll Surg 183: 25-30.

33. Bergenfelz A, Tennvall J, Valdermarsson S, Lindblom P, Tibblin S, 1997 Sestamibi versus thallium subtraction scintigraphy in parathyroid localization: a prospective comparative study in patients with predominantly mild primary hyperparathyroidism. Surgery 121: 601605.

34. Livolsi VA 2001 Morphology of the parathyroid glands. In: Becker KL (ed) Principles and Practice of Endocrinology and Metabolism, Lippincott Williams and Wilkins, Philadelphia; pp, 474-478.

35. Dell'Erba L, Baldari S, Borsato N, et al, 2001 Retrospective analysis of the association of nodular goiter with primary and secondary hyperparathyroidism. Eur J Endocrinol 145: 429-434.

36. Regal M, Paramo C, Luna Cano R, et al, 1999 Coexistence of primary hyperparathyroidism and thyroid disease. J Endocrinol Invest 22: 191-197. 